\title{
Febrile Convulsions as a Problem in Waiting Times
}

\author{
R. F. SHAW, J. C. GALL, JR. AND S. H. SCHUMAN
}

Departments of Paediatrics and Preventive Medicine and the Atlantic Research Centre for Mental Retardation, Dalhousie University, Halifax, N.S. (Canada) (R.F.S.), Plymouth State Home and Training School Plymouth, and Department of Pediatrics, The University of Michigan (J.C.G., Jr.), and Department of Epidemiology, School of Public Health, The University of Michigan (S.H.S.), Ann Arbor, Mich. (U.S.A.)

(Received 27 October, 1971)

\section{INTRODUCTION}

The so-called benign febrile convulsions represent a tendency of certain children to occasionally have seizures as a result of fever. Aithough the mode of inheritance is not known with certainty, cases are concentrated in families, and the diathesis is presumed to be genetically determined. Hence it is generally agreed that some children are constitutionally susceptible and others not.

Susceptible children can have their first attack at any time from birth to perhaps as late as the 9 th year. Subsequent febrile convulsions often follow the first one, but neither last nor first attacks occur after this time. Clearly there is a certain age range in which children prone to febrile convulsions can, in fact, suffer attacks. The occurrence of an attack in any given year during this period is very much a chance phenomenon, depending on exposure to an infection with febrile diseases, the degree of resulting fever, and perhaps other factors.

These facts have suggested to us that age at first febrile convulsion can be viewed mathematically as a problem in waiting times. Given a child with the susceptible constitution, what are the chances that he will suffer his first attack in year 1, year 2, etc? Is it possible a child will each year, by chance, escape having a convulsion until he passes the age of susceptibility? If so, how common might such children be?

In the following we give answers to these questions and suggest how these answers may relate to claims in the literature as to mode of inheritance and population frequency of the disorder as well as to its association with mental retardation and psychomotor epilepsy.

Supported by Canada National Health and Welfare Grants 602-7-127 and 635-2-4 (Dr. Shaw), U.S. National Institutes of Health Grant HD 02083 (Dr. Gall), and NHI-NIH-PHS Program Project Grant HE-06378 (Dr. Schuman).

Key words: Age of risk - Febrile convulsions - Genetics - Waiting times 


\section{MATERIAL AND METHODS}

The data to be used are from the Tecumseh Project of the School of Public Health, The University of Michigan. This is an extensive investigation into the health of the residents of the town of Tecumseh, Michigan. Response rates (which approximate $90 \%$ ) and field methods are described by Napier (1962). As part of the general health picture of each family, pediatric histories and examinations were done. As part of the pediatric survey, detailed information on febrile convulsions was obtained by interview of parents. Uniform diagnostic criteria were applied and all children reported on here were examined by a physician member of the Tecumseh Project Team.

Consider the 2077 individuals older than 7 and less than 20 years at the time of the investigation. They should be an appropriate population to study. They were not so old that parents would easily have forgotten early attacks, but they were old enough to have essentially finished the period of risk. Of these individuals 76 are recorded as having had at least one attack before the end of their 7 th year, and 3 more had their first attack at a later age, but we do not have the precise year of their first attacks (Table 1).

TABLE 1

AGE AT FIRST CONVULSION AMONG 79 CHILDREN WITH FEBRILE CONVULSIONS IN THE TECUMSEH STUDY

All were past their 7 th birthday when studied.

\begin{tabular}{cc}
\hline Year of life & No. of cases \\
\hline 1 & 27 \\
2 & 22 \\
3 & 10 \\
4 & 7 \\
5 & 5 \\
6 & 2 \\
7 & 3 \\
$(>7)$ & $(3)$ \\
& 76 through year 7 \\
& (79 all together)
\end{tabular}

The ratio $76 / 2077=3.66 \%$ gives an approximation to the true frequency of the susceptible kind of individual in the population. It will be to some degree in error for two reasons : (1) because of the 3 (all over 6 years) whose exact age at first attack is unspecified and (2) because some children, although perhaps just as susceptible as others who had attacks, may never have happened to encounter conditions sufficient to produce a convulsion. Or they may have suffered a convulsion, but one which by chance went unobserved.

The simplest hypothesis we can set up is that the probability of a first convulsion is constant over all years of the period of susceptibility. We would then expect the distribution of age at first convulsion to follow a very simple function. This is the geometric distribution $p q^{k-1}$ (Gangolli and Ylvisaker 1967) where $p$ is the yearly probability of a first convulsion and $q=1-p$. 
If $N$ individuals are at risk, in the sense of having the necessary constitution, the expected numbers of children whose first attacks occur in years $1,2,3$, up to $n$ are given by $N p q^{k-1},(k=1$ to $n)$. If this model agrees with the data, there must be values of $N$ and $p$ which lead to a good fit in the sense of a low value of chi-square. It is therefore reasonable to estimate $N$ and $p$ on the criterion of minimum chi-square, where chi-square is given by

$$
\chi^{2}=\sum_{k=1}^{7} \frac{\left(O_{k}-N p q^{k-1}\right)^{2}}{N p q^{k-1}}
$$

and the $O_{k}$ are the observed frequencies.

\section{FINDINGS}

Estimates of the parameters obtained numerically are $N=81, p=0.353$. Chi-square is 2.01 , corresponding to $P \cong 0.9$ with 6 degrees of freedom. Both this value of chisquare and the actual pattern of points as shown in Fig. 1 support the hypothesis.

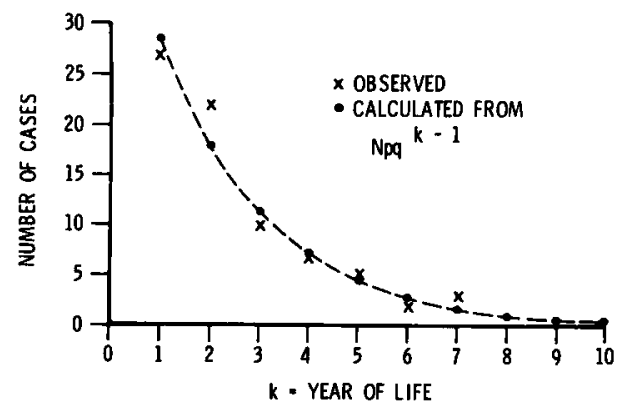

Fig. 1. Year of first febrile convulsion fitted by the geometric distribution, $N p q^{k-1}$.

It has been said that babies in their first 6 months, particularly those under 3 months of age, are different in their susceptibility to febrile convulsions or that the febrile convulsions they suffer are different in type (Millichap 1968; Ounsted 1955). If this is true, we should perhaps eliminate the first year's observations in making estimates of the parameters. The expression for chi-square is the same if we do that, but summation is over years 2-7. The estimates then become $N=85, p=0.373$, giving chi-square $1.77, P \cong 0.9$ with 5 degrees of freedom. Thus the fit is not improved by excluding the first year, and the view that the first year of life is different is not supported. (It should be noted that other sets of data may not yield the same conclusion. Van den Berg and Yerushalmy (1969) did find fewer attacks in the first year than our model would predict. At the same time, their values for later years fit very closely the model used here.) We estimate that the population must have contained $81-76=5$ susceptible children who suffered no attack (or were not observed to have an attack) in years 1-7.

It can also be concluded that, at least in the Tecumeh population, $p$, the probability of a first febrile convulsion, is indeed approximately constant over time. Yearly fluc- 
TABLE 2

PROBABILITY OF A FIRST ATTACK ACCORDING TO AGE

There are 76 observed susceptible children plus an estimate of 5 missed on the basis of the waiting time model.

\begin{tabular}{cccc}
\hline Year & $\begin{array}{c}\text { No. having } \\
\text { first attack }\end{array}$ & $\begin{array}{c}\text { No. at risk } \\
\text { in that year }\end{array}$ & $\begin{array}{c}\text { Probability } \\
\text { of a first attack }\end{array}$ \\
\hline 1 & 27 & 81 & $27 / 81=0.333$ \\
2 & 22 & 54 & $22 / 54=0.407$ \\
3 & 10 & 32 & $10 / 32=0.312$ \\
4 & 7 & 22 & $7 / 22=0.318$ \\
5 & 5 & 15 & $5 / 15=0.333$ \\
6 & 2 & 10 & $2 / 10=0.200$ \\
7 & 3 & $8^{\text {a }}$ & $3 / 8=0.375$ \\
& - & &
\end{tabular}

a This 8 includes 5 (estimated) who passed year 7 without an attack.

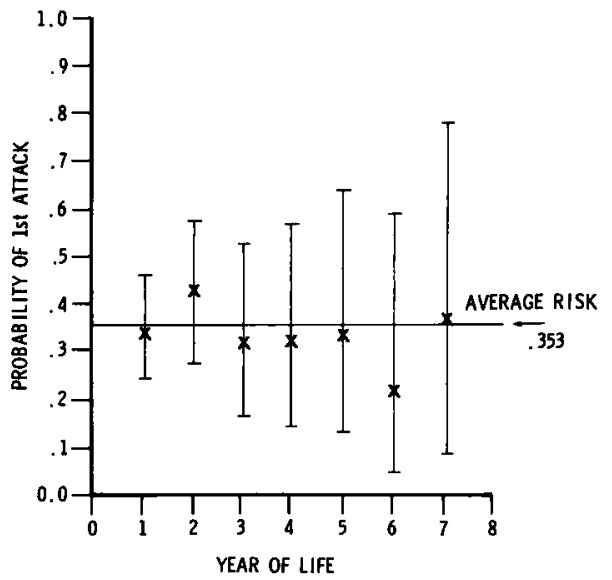

Fig. 2. Risk of first febrile convulsion as related to age. Ranges are the binomial $95 \%$ confidence limits.

tuations do, of course, occur. In Table 2 we insert the estimated 5 cases with no attack before age 7 and calculate the yearly probabilities directly. The variations by year seen there are easily explained by chance, especially as the greatest deviations are at the foot of the table where the number of persons at risk is small. The values and their $95 \%$ confidence intervals are plotted in Fig. 2.

\section{DISCUSSION}

The calculation in Table 2 is essentially the same as a life table analysis and the "probability of a first attack" given there can best be understood as analogous to the $q_{x}$ of a life table. Sometimes called "the force of mortality", $q_{x}$ is lowest for children or young adults. After maturity it increases year by year. It is indeed a measure of the force of mortiality; and its increase with advancing age corresponds to the fact that 
every year we are more susceptible to death than before. The probability of a first convulsion, in the same way, gives the year-by-year susceptibility to this kind of attack, and could be called the "force of susceptibility" to febrile convulsions. But the force of susceptibility holds steady.

Of course febrile convulsions and death differ in one important respect. A person can only die once, while he can have numerous convulsions. What, then, is the pattern of risk for febrile convulsions after the first one? Our present study tells nothing about this very interesting matter. It would be desirable to extend the analysis to second, third, and higher order attacks. Perhaps one attack predisposes to a subsequent one so that the yearly risk among children who have already had one or more attacks becomes greater.

The conclusions of the analysis can be stated as follows. Among children susceptible to febrile convulsions the risk per year of first attack is remarkably constant although it does become zero shortly after the seventh year of life. (This is not just an artifact due to the population having run out of children who still have not had their first attack. Higher order attacks also cease to occur.) In other words, the curve of risk is flat from birth until the end of the period of susceptibility, and drops precipitously at that time.

When we say that the risk of a first attack is constant with time we do not mean that it is constant in the same way that, for example, the probability of radioactive decay of an atom of an unstable element is constant. We only mean that from the data at hand, the risk appears to be roughly constant. There is no theoretical reason for any such constancy, and every reason to suppose that larger bodies of data in the future will show that, to some degree, risk changes with time. Even if the physiology of the child were not changing, surely the exposure to febrile illnesses is.

Thus the constancy we speak of is only approximate, but it is not, on that account, spurious or uninformative. It allows us to gain some insight into the question of whether the process of maturation that finally puts an end to susceptibility to the convulsions occurs gradually or suddenly. And it allows us to determine roughly how many children under circumstances like those of Tecumseh might be expected never to suffer a febrile convulsion, even though they have the same constitution as those who do.

The idea that risk in the first year of life is different from that in later years is not confirmed by the Tecumseh data. On the contrary, the risk is evidently the same. This is a surprising contradiction of clinical opinion and also disagrees with results from the other set of data we analyzed by the same method. The reason for the difference is not apparent. Perhaps the diagnostic criteria for febrile convulsions in small babies differ from one observer to another sufficiently to account for the discrepancy. Further investigation of convulsions appearing in the first year of life may be necessary to resolve the matter.

We find from the Tecumseh data that few children with the susceptible constitution can have escaped detection. More precisely, given ascertainment conditions like those of Tecumseh $76 / 81=93.8 \%$ of susceptible children can be detected by their having had at least one attack by age 7 . And the true frequency of the seizure-prone in- 
dividuals is $81 / 2077=3.90 \%$. If Frantzen et al. (1970) are correct in their assertion of simple dominant inheritance, the gene frequency in Tecumseh can be found from the expression $p^{2}+2 p q=0.0390$. Solved for $p$, this yields $p=0.0196$. The frequency of homozygotes would be $p^{2}=3.8 \times 10^{-4}$.

This leads to a further inference. In human genetics so-called dominant genes causing disease are generally provisional dominants. That is to say, they produce their effect when present in single dose, and therefore are loosely called dominants. But further study then shows that the rare homozygotes are even more seriously abnormal than the heterozygotes. If autosomal dominance is the true mode of inheritance of susceptibility to febrile convulsions we might suppose that further research will reveal the existence of individuals who have somewhat more severe manifestations, that these will be demonstrated by family studies to be homozygotes, and that their popu. lation frequency will be $p^{2}$.

There is evidence that febrile convulsions may be associated in some degree with psychomotor epilepsy (Ounsted, Lindsay and Norman 1966) and with mental retardation (Schuman and Miller 1966). Perhaps homozygosity will prove to be the cause, or partly so, of these manifestations. Unfortunately for this view, the mental retardation reported by Schuman and Miller was not present in the children who themselves had febrile convulsions, but in their seizure-free siblings. The meaning of this association is obscure.

\section{ACKNOWLEDGMENT}

We thank A. P. Smith for assistance with computations.

\section{SUMMARY}

A simple hypothesis on the occurrence of febrile convulsions is posed. This is (1) that certain children are genetically predisposed, and (2) that for such children, the probability of the first attack occurring in year 1, 2, etc., is essentially constant up to the end of the period during which the attacks can take place. These assumptions lead to a probability model which agrees well with data on age at first attack in the Town of Tecumseh, Mich. It appears that susceptibility does not gradually diminish, but rather disappears abruptly. The calculation yields an estimate of the proportion of children, among those susceptible, who will have at least one attack before they exceed the age of suceptibility.

Penetrance of the condition, measured in this way, is nearly complete: $93.8 \%$ will have manifested the condition by age 7 . The population frequency of the susceptible type of child is found to be $3.90 \%$. If one assumes the simple dominant mode of inheritance of Frantzen $e t$ al. to be correct, this estimate of population frequency leads to an estimate of the gene frequency. This is approximately $p=0.02$. The homozygote would therefore have a frequency of 4 per 10,000 . Some speculations on verifying this theory of inheritance by identifying the homozygote are given. 


\section{RÉSUMÉ}

On émet une hypothèse simple sur la survenue des convulsions fébriles, à savoir (1) que certains enfants sont génétiquement prédisposés et (2) que pour ces enfants la probabilité d'apparition de la première crise dans la première, la seconde année, etc. est essentiellement constante jusqu'à la fin de la période pendant laquelle les crises peuvent survenir. De telles suppositions conduisent à établir un modèle de probabilité qui concorde bien avec les données sur l'âge de la première crise, dans la ville de Techumseh, dans le Michigan.

Il en ressort que cette prédisposition ne diminue pas progressivement, mais au contraire, disparaît brusquement. Les calculs permettent d'estimer la proportion d'enfants prédisposés qui auront au moins une crise, avant d'avoir dépassé l'âge limite de la prédisposition.

La pénétrance de cette condition, ainsi évaluée, est presque complète: $93.8 \%$ des enfants auront manifesté cette condition à l'âge de 7 ans. La fréquence des enfants prédisposés dans la population est de $3.90 \%$.

Si l'on considère que le mode d'hérédité dominante simple de Frantzen est valable, cette estimation de la fréquence dans la population conduit à une évaluation de la fréquence du gène. Celle-ci est approximativement de $p=0.02$; l'homozygote aurait donc une fréquence de $4 / 10.000$.

Les possibilités de vérifier cette théorie des modalités héréditaires par l'identification de l'homozygote sont discutées.

(C. A. Tassinari, Marseille)

\section{REFERENCES}

Frantzen, E., Lennox-Buchthal, M., NygaARd, A. AND Stene, J., A genetic study of febrile convulsions, Neurology (Minneap.), 20: 910-917.

Gangolli, R. A. AND YlviSAKer, D., Discrete Probability, Harcourt, Brace and World, 1967, 223 pp. MillichaP, J. G., Febrile Convulsions, Macmillan, New York, 1968, 222 pp.

NAPIER, J. A., Field methods and response rates in the Tecumseh Community Health Study, Amer. J. publ. Hlth., 1962, 52: 208-216.

OUNSTED, C., Genetic and social aspects of the epilepsies of childhood, Eugen. Rev., 1955, 47: 33-49.

OUnsted, C., Lindsay, J. AND NoRman, R., Biological Factors in Temporal Lobe Epilepsy, Clinics in Developmental Medicine, No. 22, Heinemann, London, 1966, $135 \mathrm{pp}$.

SChUman, S. H. AND Miller, L. J., Febrile convulsions in families: findings in an epidemiologic survey, Clin. Pediat. (Phila.), 1966, 5:604-608.

Van Den Berg, B. and Yerushalmy, J., Studies on convulsive disorders in young children, Pediat. Res., $1969,3: 298-304$. 